\title{
Perceived Stress Among Resident Doctors in Jordanian Teaching Hospitals: Cross-Sectional Study
}

\author{
Nizar Maswadi ${ }^{1}$, MD; Yousef S Khader ${ }^{2}$, PhD; Ahmad Abu Slaih ${ }^{3}$, MPH, MD \\ ${ }^{1}$ Department of Parasitic and Zoonotic Diseases, Directorate of Communicable Diseases, Ministry of Health, Amman, Jordan \\ ${ }^{2}$ Department of Community Medicine, Public Health and Family Medicine, Jordan University of Science \& Technology, Irbid, Jordan \\ ${ }^{3}$ Community Medicine Residency Program, Jordan Ministry of Health, Amman, Jordan
}

\author{
Corresponding Author: \\ Nizar Maswadi, MD \\ Department of Parasitic and Zoonotic Diseases \\ Directorate of Communicable Diseases \\ Ministry of Health \\ Wadi as Sir, Byader, Al-Jnadweil \\ Moh'd Aqeelih Street, Building Number 7 \\ Amman, 11814 \\ Jordan \\ Phone: 962795972629 \\ Email: nizar-83@outlook.com
}

\section{Abstract}

Background: Medical residents in Jordanian hospitals are involved in many clinical and nonclinical tasks that expose them to various stress factors. High stress and burnout have the potential to negatively impact work performance and patient care, including medication errors, suboptimal care, clinical errors, and patient dissatisfaction.

Objective: This study aimed to determine the perceived stress among medical residents in Jordanian hospitals and its associated risk factors.

Methods: A cross-sectional study was conducted among residents in Jordanian hospitals. A cluster sample of 5 hospitals with residency programs was selected from different health sectors. All residents who were working in the selected hospitals were invited to participate in this study, during the period from April to July 2017. A total of 555 residents agreed to participate in this study, giving a response rate of $84 \%$. The perceived stress scale (PSS) was used for assessment.

Results: A total of 398 male and 157 female residents were included in this study. The mean PSS score in this study was 21.6; $73 \%(405 / 555)$ of the residents had moderate level of stress, and 18\% (100/555) had high level of stress. About 6.7\% (37/555) of the residents had hypertension, $2.7 \%(15 / 555)$ had diabetes, $3.2 \%(18 / 555)$ had heart disease, and 8.5\% (47/555) were anemic. $233(42 \%)$ respondents complained of back pain, and $161(29 \%)$ of the respondents complained of insomnia. Stress was associated with higher workload, sleep deprivation, and dissatisfaction in the relationship with colleagues, with income, and with the program. In multivariate analysis, the following factors were significantly associated with stress: female gender, dissatisfaction with working environment, and facing work-related, academic, and family stressors.

Conclusions: The majority of medical residents in Jordanian hospitals felt nervous and stressed. Conducting stress management programs during residency and improving the work environment are strongly recommended.

(JMIR Public Health Surveill 2019;5(4):e14238) doi: 10.2196/14238

\section{KEYWORDS}

psychology; physicians; teaching hospitals; Jordan

\section{Introduction}

Stress and psychosocial risk factors are considered critical issues in the field of occupational health [1]. Occupational stress is understood as the experience of stress that is caused by factors within the occupation or job. Occupational stress is a rational, physical, and emotional deterioration that is brought about by the dissimilarities between the job requirements and the personal skills, capabilities, and competencies. The impact of stress on the physical and mental health, as well as the productivity of 
both the organizations and the employees, is a growing concern of organizations. High stress and burnout have the potential to negatively impact work performance and patient care, including medication errors, suboptimal care, clinical errors, and patient dissatisfaction [2,3]. Many studies have looked into the stress and the burnout levels of medical personnel, and an extremely high level of stress has been observed in hospital nurses, surgeons, general practitioners, and resident doctors [4,5]. Physicians are exposed to many stressors, such as the burden imposed by the expectations of a high degree of professionalism, responsibility for patient well-being, and maintenance of relationships with patients and health workers, as well as concerns about medical errors and malpractice litigation [6]. Studies have demonstrated that up to $76 \%$ of residents meet the criteria for burnout and that they have expressed career dissatisfaction, as well as concern that they provide suboptimal patient care [1]. Residents report that the working conditions they are subjected to during residency lead to reduced attention, empathy, concern, and sensitivity, and increased irritability, abruptness, and a tendency to objectify patients [7]. The significance of this study emerges from the fact that the quality of health care can be extremely influenced by the stressed health staff. Residency involves long hours, large numbers of patients, and sleep deprivation $[8,9]$. When the level of stress exceeds a critical level, it can manifest as distress, resulting in psychological morbidity, impairment, and burnout [10]. This study aimed to assess the level of stress among residents and determine the main leading factors causing stress among resident doctors in Jordanian hospitals.

\section{Methods}

\section{Study Design}

This cross-sectional study was conducted among medical residents trained in different residency programs in Jordan, during the period from April to July 2017. All residents who were enrolled in different sectors, including public, private, and teaching programs, were eligible to be included in the study. Al-Bashir and Prince Hamza hospitals were selected from the public sector, Islamic hospital and Jordan hospital were selected from the private sector, and King Abdullah University hospital was selected from the teaching health sector. All residents who were working in the selected hospitals were invited to participate in this study. A total of 555 residents agreed to participate in this study, giving a response rate of $84 \%$. The ethical approval was obtained from the Institutional Review Board at the Ministry of Health in Jordan.

\section{Data Collection}

A self-administrated questionnaire was used to collect the data. The questionnaire included data on sociodemographic characteristics (age, gender, and marital status), residency characteristics (specialty and year), diseases or symptoms experienced by medical residents in the last year, workload (number of inpatients and outpatients treated per day, sleep duration, and quality), recently faced stressors (work related and nonwork related), and job satisfaction. Perceived stress scale (PSS) was used to assess residents' perception of stress over the past month [11]. The respondents answered each PSS question on a Likert-type scale (never, almost never, sometimes, fairly often, or very often). We scored the answers to questions $1,2,3,6,9$, and 10 by giving a score of 0 to the "never" answers and 4 to the "very often" responses. Questions 4, 5, 7, and 8 were scored by scoring "never" as 4 and "very often" as 0 . The PSS score was calculated by summing up the scores of all the individual questions. Scores ranging from 0 to 13 would be considered low stress, scores ranging from 14 to 26 would be considered moderate stress, and scores ranging from 27 to 40 would be considered high perceived stress, with higher scores indicating higher levels of stress. The PSS had good internal consistency among its items, as indicated by an overall Cornbrash alpha value of .76. The study questionnaire was pilot tested on 30 participants $(n=30)$. Necessary changes on the wording and phrasing of the questions were revised according to the pilot study findings. The face and content validity of the study questionnaire were evaluated by 3 experts.

\section{Statistical Analysis}

Data were coded and entered through IBM SPSS, version 20, software. Data were described using percentages and means. Variables were displayed through percentage frequency tables. Comparisons between 2 means and more than 2 means were tested for statistical significance by using an independent $t$ test and a 1-way analysis of variance, respectively. General linear model was used to test the factors associated with stress level in the multivariate analysis. A $P$ value $<.05$ was considered statistically significant.

\section{Results}

\section{Characteristics of the Participants}

A total of $398(71.7 \%, 398 / 555)$ male and 157 (28.3\%, 157/555) female residents were included in this study. Table 1 shows their sociodemographic and work characteristics.

The average (SD) age was 30.0 (3.0) years. More than half of respondents were residents in the fields of surgery, internal medicine, pediatrics, and radiology. A majority of the participants $(92 \%, 511 / 555)$ worked night shift, and $95.3 \%$ $(529 / 555)$ dealt with emergency cases. The median number of inpatients and outpatients treated by the residents per day was 15 and 35 patients, respectively. Approximately $78.9 \%$ $(435 / 555)$ of the residents reported that they slept for less than 6 hours per day, and only $21.4 \%(119 / 555)$ of the residents reported feeling refreshed after sleep.

Depending on self-reported data, about $6.7 \%$ (37/555) of the residents had hypertension, $2.7 \%(15 / 555)$ had diabetes, $3.2 \%$ $(18 / 555)$ had heart disease, $8.5 \%$ (47/555) were anemic, and $7.0 \%(39 / 555)$ had lung or breathing problems. $233(42 \%)$ respondents complained of back pain, $161(29 \%)$ complained of insomnia, $83(15 \%)$ of stomach ulcer, $78(14 \%)$ of gastritis, $67(12 \%)$ of emotional problems, and $50(9 \%)$ colitis. 
Table 1. The sociodemographic and work characteristics of medical residents in Jordanian hospitals ( $\mathrm{N}=555)$.

\begin{tabular}{|c|c|}
\hline Characteristics & Statistics, n (\%) \\
\hline \multicolumn{2}{|l|}{ Gender } \\
\hline Male & $398(71.7)$ \\
\hline Female & $157(28.3)$ \\
\hline \multicolumn{2}{|l|}{ Age (years) } \\
\hline$<30$ & $267(51.0)$ \\
\hline$\geq 30$ & $257(49.0)$ \\
\hline \multicolumn{2}{|l|}{ Marital status } \\
\hline Married & $323(58.2)$ \\
\hline Single & $232(41.8)$ \\
\hline \multicolumn{2}{|l|}{ Specialty } \\
\hline Surgery & $110(19.8)$ \\
\hline Internal medicine & $85(15.3)$ \\
\hline Pediatrics & $84(15.1)$ \\
\hline Radiology & $61(11.0)$ \\
\hline Anesthesia & $43(7.7)$ \\
\hline Obstetrics and gynecology & $38(6.8)$ \\
\hline Orthopedics & $35(6.3)$ \\
\hline Others & $99(17.8)$ \\
\hline \multicolumn{2}{|l|}{ Residency year } \\
\hline First & $162(29.2)$ \\
\hline Second & $124(22.3)$ \\
\hline Third & $104(18.7)$ \\
\hline Fourth & $103(18.6)$ \\
\hline Fifth & $62(11.2)$ \\
\hline \multicolumn{2}{|l|}{ Night shift per month } \\
\hline $1-5$ & $133(24.0)$ \\
\hline$>5$ & $378(68.1)$ \\
\hline Deal with emergency cases & $529(95.3)$ \\
\hline \multicolumn{2}{|l|}{ Inpatients treated per day } \\
\hline$\leq 15$ & $282(50.1)$ \\
\hline$>15$ & $241(49.9)$ \\
\hline \multicolumn{2}{|l|}{ Outpatients treated per day } \\
\hline$\leq 35$ & $258(50.1)$ \\
\hline$>35$ & $257(49.9)$ \\
\hline \multicolumn{2}{|l|}{ Sleep duration (hours) } \\
\hline$\leq 5$ & $225(40.8)$ \\
\hline 6 & $210(38.1)$ \\
\hline 7 & $80(14.5)$ \\
\hline$\geq 8$ & $36(6.5)$ \\
\hline Feeling refreshed after sleep & $119(21.4)$ \\
\hline
\end{tabular}




\section{Stressors and Satisfaction}

Table 2 shows stressors, job satisfaction, and ideation among the study participants. The most commonly reported stressors included work-related, financial, academic, and family stressors.

About $70.0 \%$ (388/555) of the participants were satisfied with their relationship with colleagues; $21.1 \%$ (117/555) of the participants were satisfied with the training program, whereas $14 \%(78 / 555)$ of the participants were dissatisfied. A total of $15.7 \%(87 / 555)$ of the residents frequently considered changing their specialty, and $23.6 \%$ (131/555) had frequent thoughts of quitting the medical profession.

Table 2. Stressors, job satisfaction, and ideation experienced by medical residents in Jordanian hospitals.

\begin{tabular}{|c|c|}
\hline Characteristics & Statistics, $\mathrm{n}(\%)$ \\
\hline Comfortable working environment & $86(15.5)$ \\
\hline Satisfied with income & $30(5.4)$ \\
\hline \multicolumn{2}{|l|}{ Facing stressors experienced in the last month } \\
\hline Work related & $479(86.3)$ \\
\hline Financial & $345(62.2)$ \\
\hline Academic & $290(52.3)$ \\
\hline Family & $126(22.7)$ \\
\hline Alienation & $74(13.3)$ \\
\hline Death & $19(3.4)$ \\
\hline Others & $82(14.8)$ \\
\hline Satisfied with the relationships with colleagues & $388(70.0)$ \\
\hline Satisfied with training program & $117(21.1)$ \\
\hline \multicolumn{2}{|l|}{ Thoughts of changing specialty } \\
\hline Very often & $87(15.7)$ \\
\hline Sometimes & $198(35.7)$ \\
\hline Rarely & $104(18.7)$ \\
\hline Never & $166(29.9)$ \\
\hline \multicolumn{2}{|l|}{ Thoughts of quitting } \\
\hline Very often & $131(23.6)$ \\
\hline Sometimes & $205(36.9)$ \\
\hline Rarely & $94(16.9)$ \\
\hline Never & $125(22.5)$ \\
\hline
\end{tabular}

\section{Responses to Perceived Stress Scale}

A majority of the medical residents $(73 \%, 405 / 555)$ had moderate level of stress, $18 \%$ (100/555) of the medical residents had high level of stress, and 9\% (50/555) had mild level of stress. Table 3 shows the responses to PSS.

During the last month preceding the survey, $76.2 \%$ (423/555) of the residents often ("fairly" or "very") felt nervous and stressed, $44.8 \%(249 / 555)$ felt upset because of unexpected events, $45.8 \%(254 / 555)$ felt angered by circumstances that were beyond their control, $42.4 \%$ (235/555) felt unable to control important things in their life, and $44.1 \%$ (245/555) felt that difficulties were piling up, which were too high to overcome. In contrast, $34.7 \%$ (193/555) of the residents often felt that things were going their way, $20.5 \%$ (114/555) felt that they were on top of things, $19.7 \%(109 / 555)$ had often been able to control irritations in their life, and $15.4 \%$ (85/555) often felt confident in their ability to handle personal problems. 
Table 3. Medical residents' responses to perceived stress scale in Jordanian hospitals.

\begin{tabular}{|c|c|c|c|c|c|}
\hline Perceived stress scale items & Never, n (\%) & $\begin{array}{l}\text { Almost never, } \mathrm{n} \\
(\%)\end{array}$ & $\begin{array}{l}\text { Sometimes, } \mathrm{n} \\
(\%)\end{array}$ & $\begin{array}{l}\text { Fairly often, } \mathrm{n} \\
(\%)\end{array}$ & $\begin{array}{l}\text { Very often, } \mathrm{n} \\
(\%)\end{array}$ \\
\hline $\begin{array}{l}\text { In the last month, how often have you been upset because } \\
\text { of something that happened unexpectedly? }\end{array}$ & $41(7.4)$ & $63(11.4)$ & $202(36.4)$ & $150(27.0)$ & $99(17.8)$ \\
\hline $\begin{array}{l}\text { In the last month, how often have you felt that you were } \\
\text { unable to control the important things in your life? }\end{array}$ & $44(7.9)$ & $96(17.3)$ & $180(32.4)$ & $147(26.5)$ & $88(15.9)$ \\
\hline $\begin{array}{l}\text { In the last month, how often have you felt nervous and } \\
\text { "stressed?" }\end{array}$ & $8(1.4)$ & $19(3.4)$ & $105(18.9)$ & $197(35.5)$ & $226(40.7)$ \\
\hline $\begin{array}{l}\text { In the last month, how often have you felt confident about } \\
\text { your ability to handle your personal problems? }\end{array}$ & $99(17.8)$ & $178(32.1)$ & $193(34.8)$ & $68(12.3)$ & $17(3.1)$ \\
\hline $\begin{array}{l}\text { In the last month, how often have you felt that things were } \\
\text { going your way? }\end{array}$ & $25(4.5)$ & $104(18.7)$ & $233(42.0)$ & $129(23.2)$ & $64(11.5)$ \\
\hline $\begin{array}{l}\text { In the last month, how often have you found that you could } \\
\text { not cope with all the things that you had to do? }\end{array}$ & $31(5.6)$ & $107(19.3)$ & $234(42.2)$ & $135(24.3)$ & $48(8.6)$ \\
\hline $\begin{array}{l}\text { In the last month, how often have you been able to control } \\
\text { irritations in your life? }\end{array}$ & $66(11.9)$ & $195(35.1)$ & $185(33.3)$ & $82(14.8)$ & $27(4.9)$ \\
\hline $\begin{array}{l}\text { In the last month, how often have you felt that you were } \\
\text { on top of things? }\end{array}$ & $53(9.5)$ & $179(32.3)$ & $209(37.7)$ & $79(14.2)$ & $35(6.3)$ \\
\hline $\begin{array}{l}\text { In the last month, how often have you been angered because } \\
\text { of things that were outside of your control? }\end{array}$ & $22(4.0)$ & $75(13.5)$ & $204(36.8)$ & $171(30.8)$ & $83(15.0)$ \\
\hline $\begin{array}{l}\text { In the last month, how often have you felt difficulties were } \\
\text { piling up so high that you could not overcome them? }\end{array}$ & $19(3.4)$ & $96(17.3)$ & $195(35.1)$ & $164(29.5)$ & $81(14.6)$ \\
\hline
\end{tabular}

\section{Thoughts of Changing Specialty and Quitting Work According to Stress Level}

Figure 1 shows that a quarter of the residents with high level of stress were always thinking of changing specialty, whereas $43 \%(239 / 555)$ of the residents were sometimes thinking of changing specialty. About two-thirds of the residents (361/555, $65 \%$ ) with low level of stress had never thought of changing specialty. Figure 2 shows that $37 \%(205 / 555)$ of the residents with high level of stress were always thinking of quitting work, whereas two-thirds $(350 / 555,63 \%)$ of the residents with low level of stress had never thought of quitting work.

Figure 1. Percentage of residents who thought of changing specialty according to stress level.

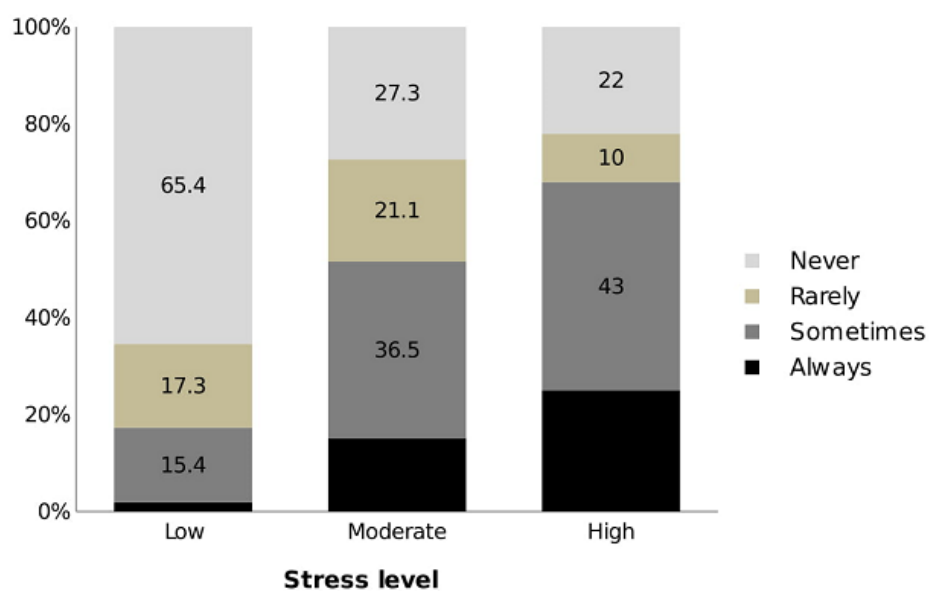


Figure 2. Percentage of residents who thought quitting work according to stress level.

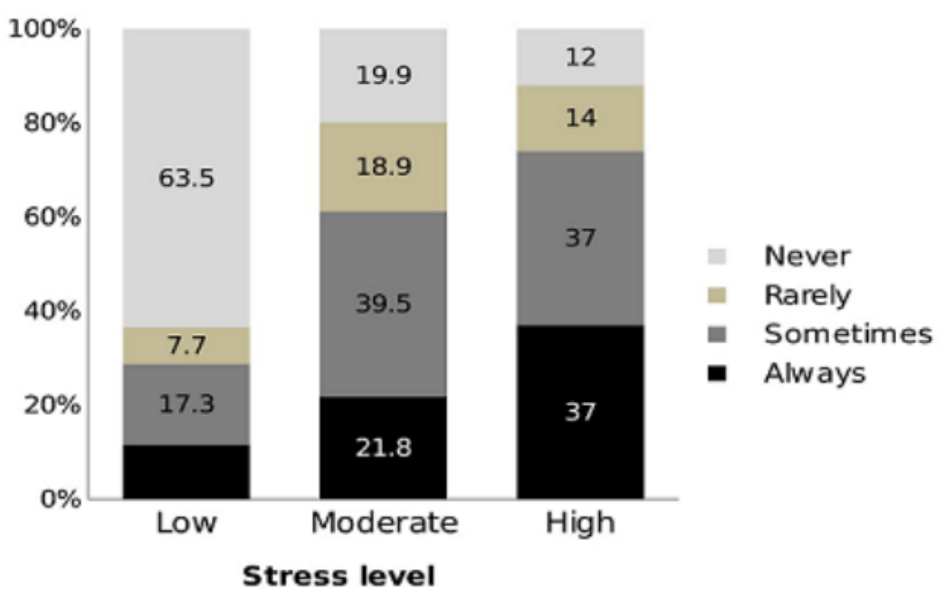

\section{Stress Level and Its Associated Factors}

The mean (SD) of the PSS scores was 21.6 (5.8). The average PSS scores, according to sociodemographic and work characteristics and level of satisfaction, are shown in Table 4.

The average PSS score differed significantly according to gender, specialty, night shifts, number of inpatients treated per day, number of outpatients treated per day, satisfaction with working environment, satisfaction with income, satisfaction with the relationships with colleagues, and satisfaction with training program. Table 5 shows the average PSS score according to stressors experienced by residents. Stress level was significantly associated with work-related stressors, financial stressors, academic stressors, and family-related stressors.

Table 6 shows multivariate analysis of factors associated with mean PSS score. Stress level was significantly higher among females, in those working in uncomfortable environments, and in those with work-related, academic-related, and family-related stressors. Those with anemia also had a higher stress level. 
Table 4. The average perceived stress scale score according to sociodemographic and work characteristics and level of satisfaction.

\begin{tabular}{|c|c|c|}
\hline Characteristics & Mean (SD) & $P$ value \\
\hline Age (years) & & .49 \\
\hline$<30$ & $21.8(5.68)$ & $-^{\mathrm{a}}$ \\
\hline$\geq 30$ & $21.4(5.86)$ & - \\
\hline Gender & & $<.001$ \\
\hline Male & $21.0(5.69)$ & - \\
\hline Female & $23.3(5.88)$ & - \\
\hline Marital status & & .74 \\
\hline Married & $21.7(5.63)$ & - \\
\hline Single & $21.5(6.13)$ & - \\
\hline Specialty & & .02 \\
\hline Surgery & $21.6(6.30)$ & - \\
\hline Internal medicine & $22.2(5.98)$ & - \\
\hline Pediatrics & $22.2(5.55)$ & - \\
\hline Radiology & $20.5(6.42)$ & - \\
\hline Anesthesia & $19.2(4.92)$ & - \\
\hline Obstetrics and gynecology & $23.6(5.43)$ & - \\
\hline Orthopedics & $22.6(5.14)$ & - \\
\hline Others & $21.4(5.49)$ & - \\
\hline Residency years & & .33 \\
\hline First & $21.3(5.68)$ & - \\
\hline Second & $22.5(5.93)$ & - \\
\hline Third & $21.8(5.96)$ & - \\
\hline Fourth & $21.2(5.94)$ & - \\
\hline Fifth & $21.0(5.64)$ & - \\
\hline Emergency cases & & .65 \\
\hline Yes & $21.6(5.79)$ & - \\
\hline No & $22.1(6.74)$ & - \\
\hline Night shift & & .005 \\
\hline $1-5$ & $20.2(6.17)$ & - \\
\hline$>5$ & $22.0(5.69)$ & - \\
\hline Inpatients treated per day & & .02 \\
\hline$\leq 15$ & $21.0(6.02)$ & - \\
\hline$>15$ & $22.3(5.61)$ & - \\
\hline Outpatients treated per day & & .007 \\
\hline$\leq 35$ & $20.8(5.88)$ & - \\
\hline$>35$ & $22.2(5.56)$ & - \\
\hline Comfortable working environment & & $<.001$ \\
\hline Yes & $17.7(6.16)$ & - \\
\hline No & $22.3(5.49)$ & - \\
\hline Satisfied with income & & .002 \\
\hline Yes & $18.4(5.94)$ & - \\
\hline No & $21.8(5.78)$ & - \\
\hline
\end{tabular}




\begin{tabular}{lll}
\hline Characteristics & Mean (SD) & $P$ value \\
\hline Satisfied with the relationships with colleagues & & $<.001$ \\
$\quad$ Satisfied & $20.9(5.89)$ & - \\
Dissatisfied & $23.5(5.30)$ & - \\
Not sure & $23.4(5.36)$ & $<.001$ \\
Satisfied with training program & - & - \\
Satisfied & $19.2(5.91)$ & - \\
Dissatisfied & $22.6(5.67)$ & - \\
Not sure & $21.4(5.32)$ & \\
\hline
\end{tabular}

${ }^{\mathrm{a}}$ Not applicable.

Table 5. The average perceived stress scale score according to stressors experienced by medical residents in Jordanian hospitals.

\begin{tabular}{|c|c|c|}
\hline Characteristics & Mean (SD) & $P$ value \\
\hline Work related & & $<.001$ \\
\hline Yes & $22.2(5.53)$ & $-^{\mathrm{a}}$ \\
\hline No & $18.1(6.47)$ & - \\
\hline Financial & & $<.001$ \\
\hline Yes & $22.5(5.92)$ & - \\
\hline No & $20.2(5.42)$ & - \\
\hline Academic & & $<.001$ \\
\hline Yes & $23.0(5.65)$ & - \\
\hline No & $20.1(5.69)$ & - \\
\hline Family & & $<.001$ \\
\hline Yes & $23.8(5.41)$ & - \\
\hline No & $21.0(5.81)$ & - \\
\hline Alienation & & .65 \\
\hline Yes & $21.9(5.92)$ & - \\
\hline No & $21.6(5.83)$ & - \\
\hline Death & & .12 \\
\hline Yes & $23.7(6.25)$ & - \\
\hline No & $21.6(5.81)$ & - \\
\hline
\end{tabular}

${ }^{\mathrm{a}}$ Not applicable. 
Table 6. Multivariate analysis of factors associated with mean perceived stress scale score.

\begin{tabular}{|c|c|c|c|}
\hline Characteristics & Mean (SE) & $95 \% \mathrm{CI}$ & $P$ value \\
\hline Gender & & & .002 \\
\hline Male & $20.2(0.6)$ & $19.0-21.3$ & $-^{\mathrm{a}}$ \\
\hline Female & $22.0(0.6)$ & $20.9-23.2$ & - \\
\hline Specialty & & & .15 \\
\hline Anesthesia & $19.3(0.9)$ & $17.5-21.1$ & - \\
\hline Radiology & $21.1(0.8)$ & $19.6-22.7$ & - \\
\hline Surgery & $21.7(0.7)$ & $20.3-23.1$ & - \\
\hline Internal medicine & $22.0(0.8)$ & $20.5-23.5$ & - \\
\hline Obstetric & $20.8(1.0)$ & $18.8-22.7$ & - \\
\hline Orthopedic & $22.2(1.0)$ & $20.2-24.3$ & - \\
\hline Pediatric & $20.7(0.7)$ & $19.3-22.2$ & - \\
\hline Others & $21.0(0.7)$ & $19.7-22.3$ & - \\
\hline \multicolumn{2}{|c|}{ Comfortable working environment } & & $<.001$ \\
\hline Yes & $19.2(0.7)$ & $17.8-20.5$ & - \\
\hline No & $23.1(0.5)$ & $22.0-24.1$ & - \\
\hline Work related & & & $<.001$ \\
\hline Yes & $22.4(0.5)$ & $21.4-23.8$ & - \\
\hline No & $19.9(0.7)$ & $18.5-21.3$ & - \\
\hline Academic related & & & $<.001$ \\
\hline Yes & $22.2(0.5)$ & $21.1-23.2$ & - \\
\hline No & $20.0(0.5)$ & $18.9-21.2$ & - \\
\hline Family related & & & .001 \\
\hline Yes & $22.0(0.6)$ & $20.7-23.3$ & - \\
\hline No & $20.2(0.5)$ & $19.2-21.2$ & - \\
\hline Anemia & & & .007 \\
\hline Yes & $22.3(0.8)$ & $20.6-23.9$ & - \\
\hline No & $19.9(0.4)$ & $19.1-20.8$ & - \\
\hline
\end{tabular}

${ }^{\mathrm{a}}$ Not applicable.

\section{Discussion}

Work-related stress is very common among health care workers. Health care providers around the world are subject to pressures resulting from a sharp escalation of change, growing economic pressures, technological advances, increasing patient expectations, rationing of health care, and the requirement for more evidence-based and high-quality health care, improved performance, and productivity. It is well documented that health workers experience higher levels of stress and stress-related health problems than other occupational groups [12].

To the best of our knowledge, this study was the first to determine the magnitude of perceived stress among medical residents in Jordan. The study included residents of various specialties from different health sectors.
The study showed that the majority of medical residents had a moderate level of stress $(405 / 555,73 \%)$, and 18\% (100/555) of the medical residents had a high level of stress. The perceived stress among residents in this study was comparable with the perceived stress reported among residents in other parts of the world. The mean PSS score in this study was 21.6. This mean is almost the same score for 938 medical residents in Saudi Arabia, where they reported a mean score of 22 [13]. Similarly, the mean PSS score was 21.7 in 106 cardiology residents in Argentina [14], and 19.9 among 159 anesthesia residents in Turkey [15]. A lower score of 16.1 had been reported among 168 family medicine residents in the United States [16]. On the other hand, a study among 84 doctors working in a tertiary care teaching hospital in India reported a mean of 18.3, and another study reported a mean of 18 among 303 physicians working in an Asser region in Saudi Arabia [17-19]. 
The variations in the PSS score in different studies might be explained by many factors, such as working environment, the specialty, and differences in sociodemographic and cultural characteristics. However, the variations among these studies are not clinically significant.

During the 30 days preceding the survey, $76.2 \%$ (423/555) of the residents ("fairly" or "very") felt nervous and stressed, which can be considered higher than other countries in the region, such as Saudi Arabia, where the $68.2 \%$ of the medical residents reported being under stress. On the other side, 19.7\% (109/555) of the residents in our sample had often been able to control irritations in their life, in comparison with $34.7 \%$ of the Saudi residents [13]. Unfortunately, there is a lack of studies that examine stress among residents in Jordan; therefore, the study compares the findings with the perceived stress among nursing students in Jordan, as the mean of the PSS was 45.9 [20].

According to stress and the personal characteristics, female residents had a significantly higher level of stress than male residents, which was identified by multiregression analysis. There are several studies in agreement with our findings [21,22]. The reasons for this difference should be considered, as more serious consequences might occur among the female physicians who face more workplace adversity compared with males experiencing the same level of occupational stress, in terms of mistrust from the patients, as well as having the dual responsibilities of career and family.

In our multivariate results, stress was significantly associated with anemia; one of the most common symptoms of anemia is a feeling of fatigue and a lack of energy, and although the pathogenesis of anemia-related fatigue remains unclear, some suggest that abnormalities in energy metabolism play a role in inducing fatigue [23]. The relationship between anemia and fatigue is universally accepted. However, early studies were unable to show a clear association between fatigue and hemoglobin levels. There was no evidence of an association between iron deficiency and fatigue in the absence of anemia, suggesting that iron deficiency is not a clinically relevant contributor to fatigue. This gives an important insight for the need to conduct further investigations on the association between anemia and fatigue.

Stress was significantly associated with obstetrics and gynecology residents, surgery, internal medicine, and pediatrics in most countries. It is a well-known fact that the obstetrics and gynecology residency has the highest prevalence of burnout among all specialties [22]. This is explained by the fact that residency in obstetrics and gynecology in most countries is characterized by sleep deprivation, long weekly working hours, postcall clinical responsibilities, and professional liability insurance crises.

The residents in this study, who shouldered higher workloads (dealing with more patients and working more night shifts) and who suffered from sleep deprivation (sleeping few hours and feeling unrefreshed after sleep), were at higher risk of stress. The findings of this study replicate findings from previous studies that used various stress measurement tools to identify the parameters associated with higher stress in residents, such as prolonged working hours, high patient load, critical patients assigned, night duty, poor sleep duration, and quality, poor work environment, and process failure $[13,16]$. The importance of prolonged working hours in causing fatigue and sleep deprivation, which consequently caused stress, led to the legal restriction of residents' weekly working hours in the United States in 2003 [23]. This restriction probably had a positive impact on the well-being of the residents. Nonetheless, another study has shown that prolonged working hours may be responsible for both stress and decreased job satisfaction among residents. Unfortunately, most of the residents never received efficient or professional stress management.

The stressors associated with stress in this study covered the 3 groups of stressors described earlier: institutional, professional, and personal stressors [10]. The respondents' stress was associated with dissatisfaction with colleagues and dissatisfaction with training program, income, and frequent thoughts of quitting the medical profession. This dissatisfaction might cause the stress or vice versa, which indicates a need for stress management programs during residency.

In conclusion, the degree of work-related stress among residents in Jordanian hospitals is considerably moderate to high. The most important significant risk factors identified by multiregression analysis were the following: facing work-related stressors, academic-related stressors, family-related stressors, and uncomfortable work environment. Establishment of professional counseling for the residents is highly recommended to deal with their issues in a timely manner that would support their needs. This could lead to an enhancement in the working environment.

\section{Acknowledgments}

The authors would like to thank The Eastern Mediterranean Public Health Network for its technical support.

\section{Conflicts of Interest}

None declared.

\section{References}

1. Wallace JE, Lemaire JB, Ghali WA. Physician wellness: a missing quality indicator. Lancet 2009 Nov 14;374(9702):1714-1721. [doi: 10.1016/S0140-6736(09)61424-0] [Medline: 19914516 ]

2. West CP, Shanafelt TD, Kolars JC. Quality of life, burnout, educational debt, and medical knowledge among internal medicine residents. J Am Med Assoc 2011 Sep 7;306(9):952-960. [doi: 10.1001/jama.2011.1247] [Medline: 21900135] 
3. Mumtaz Y, Jahangeer A, Habib A, Adnan S, Mumtaz Z. Stress in postgraduate trainee doctors of public and private Universities of Karachi. Pak J Med Sci 2010;26(2):420-425 [FREE Full text]

4. Potter P, Deshields T, Divanbeigi J, Berger J, Cipriano D, Norris L, et al. Compassion fatigue and burnout: prevalence among oncology nurses. Clin J Oncol Nurs 2010 Oct;14(5):E56-E62 [FREE Full text] [doi: 10.1188/10.CJON.E56-E62] [Medline: 20880809]

5. Beckman TJ, Reed DA, Shanafelt TD, West CP. Resident physician well-being and assessments of their knowledge and clinical performance. J Gen Intern Med 2012 Mar;27(3):325-330 [FREE Full text] [doi: 10.1007/s11606-011-1891-6] [Medline: 21948207]

6. Firth-Cozens J. Interventions to improve physicians' well-being and patient care. Soc Sci Med 2001 Jan;52(2):215-222. [doi: 10.1016/s0277-9536(00)00221-5] [Medline: 11144777]

7. Papp KK, Stoller EP, Sage P, Aikens JE, Owens J, Avidan A, et al. The effects of sleep loss and fatigue on resident-physicians: a multi-institutional, mixed-method study. Acad Med 2004 May;79(5):394-406. [doi: 10.1097/00001888-200405000-00007] [Medline: 15107278]

8. Rockey PH. Duty hours: where do we go from here? Mayo Clin Proc 2011 Mar;86(3):176-178 [FREE Full text] [doi: 10.4065/mcp.2011.0086] [Medline: 21364108]

9. Levey RE. Sources of stress for residents and recommendations for programs to assist them. Acad Med 2001 Feb;76(2):142-150. [doi: 10.1097/00001888-200102000-00010] [Medline: 11158832]

10. Cohen S, Kamarck T, Mermelstein R. A global measure of perceived stress. J Health Soc Behav 1983 Dec;24(4):385-396. [doi: 10.2307/2136404] [Medline: 6668417]

11. Lemaire JB, Wallace JE. Not all coping strategies are created equal: a mixed methods study exploring physicians' self reported coping strategies. BMC Health Serv Res 2010 Jul 14;10:208-217 [FREE Full text] [doi: 10.1186/1472-6963-10-208] [Medline: 20630091]

12. Alosaimi FD, Kazim SN, Almufleh AS, Aladwani BS, Alsubaie AS. Prevalence of stress and its determinants among residents in Saudi Arabia. Saudi Med J 2015 May;36(5):605-612 [FREE Full text] [doi: 10.15537/smj.2015.5.10814] [Medline: 25935183]

13. Waldman SV, Diez JC, Arazi HC, Linetzky B, Guinjoan S, Grancelli H. Burnout, perceived stress, and depression among cardiology residents in Argentina. Acad Psychiatry 2009;33(4):296-301. [doi: 10.1176/appi.ap.33.4.296] [Medline: 19690109]

14. Abut YC, Kitapcioglu D, Erkalp K, Toprak N, Boztepe A, Sivrikaya U, et al. Job burnout in 159 anesthesiology trainees. Saudi J Anaesth 2012 Jan;6(1):46-51 [FREE Full text] [doi: 10.4103/1658-354X.93059] [Medline: 22412777]

15. Lebensohn P, Dodds S, Benn R, Brooks AJ, Birch M, Cook P, et al. Resident wellness behaviors: relationship to stress, depression, and burnout. Fam Med 2013 Sep;45(8):541-549 [FREE Full text] [Medline: 24129866]

16. Sathiya N, Ruwaidha R, Nusrath FS, Fathima F, Gomathy T, Shailendra HK. Perceived stress levels and its sources among doctors and nurses working in a tertiary care teaching hospital, Kancheepuram, Tamil Nadu. Ntl J Community Med 2016;7(7):603-608 [FREE Full text]

17. Siddiqui AF, Zaalah MA, Alqahtani AA, Alqahtani MA. Perceived stress and its associated sociodemographic factors among physicians working in Aseer region of Saudi Arabia. J Liaquat Uni Med Health Sci 2017;16(1):10-18. [doi: 10.1177/1708538116636250] [Medline: 27083699]

18. Akhu-Zaheya L, Shaban I, Khater W. Nursing students' perceived stress and influences in clinical performance. Int J Adv Nurs Stud 2015 Jun 17;4(2):44. [doi: 10.14419/ijans.v4i2.4311]

19. Kama AA, Sabbour SM, Habeel IS, Ghanem EA. Prevalence and risk factors of work related stress among residents at Ain Shams University Hospitals. Egypt J Commun Med 2015 Jul 1;33(3):81-98. [doi: 10.21608/ejcm.2015.704]

20. Alosaimi FD, Almufleh A, Kazim S, Aladwani B. Stress-coping strategies among medical residents in Saudi Arabia: a cross-sectional national study. Pak J Med Sci 2015;31(3):504-509 [FREE Full text] [doi: 10.12669/pjms.313.7490] [Medline: 26150833]

21. Sobrero A, Puglisi F, Guglielmi A, Belvedere O, Aprile G, Ramello M, et al. Fatigue: a main component of anemia symptomatology. Semin Oncol 2001 Apr;28(2 Suppl 8):15-18. [doi: 10.1016/s0093-7754(01)90207-6] [Medline: 11395847]

22. Martini S, Arfken CL, Churchill A, Balon R. Burnout comparison among residents in different medical specialties. Acad Psychiatry 2004;28(3):240-242. [doi: 10.1176/appi.ap.28.3.240] [Medline: 15507560]

23. Zaré SM, Galanko J, Behrns KE, Koruda MJ, Boyle LM, Farley DR, et al. Psychological well-being of surgery residents before the 80-hour work week: a multiinstitutional study. J Am Coll Surg 2004 Apr;198(4):633-640. [doi: 10.1016/j.jamcollsurg.2003.10.006] [Medline: 15051017]

\section{Abbreviations}

PSS: perceived stress scale 
Edited by H Abbas; submitted 02.04.19; peer-reviewed by O Beni Yonis, M Khatatbeh, S Kardes; comments to author 03.07.19; revised version received 15.07.19; accepted 15.07.19; published 02.10.19

Please cite as:

Maswadi N, Khader YS, Abu Slaih A

Perceived Stress Among Resident Doctors in Jordanian Teaching Hospitals: Cross-Sectional Study

JMIR Public Health Surveill 2019;5(4):e14238

URL: https://publichealth.jmir.org/2019/4/e14238

doi: $10.2196 / 14238$

PMID: 31579024

CNizar Maswadi, Yousef S Khader, Ahmad Abu Slaih. Originally published in JMIR Public Health and Surveillance (http://publichealth.jmir.org), 02.10.2019 This is an open-access article distributed under the terms of the Creative Commons Attribution License (https://creativecommons.org/licenses/by/4.0/), which permits unrestricted use, distribution, and reproduction in any medium, provided the original work, first published in JMIR Public Health and Surveillance, is properly cited. The complete bibliographic information, a link to the original publication on http://publichealth.jmir.org, as well as this copyright and license information must be included. 